BMJ Nutrition, Prevention \& Health

\section{Vietnam a country in transition: health challenges}

To cite: Nguyen TT, Trevisan M. Vietnam a country in transition: health challenges. BMJ Nutrition, Prevention \& Health 2020;3:e000069. doi:10.1136/ bmjnph-2020-000069

College of Health Sciences, VinUniversity, Ha Noi, Vietnam

Correspondence to Dr Tuyet Thi Nguyen, College of Health Sciences, VinUniversity, Ha Noi, Viet Nam; v.tuyetnt10@vingroup.net

Received 5 March 2020 Revised 7 April 2020 Accepted 16 April 2020 Published Online First 6 May 2020
Check for updates

(C) Author(s) (or their employer(s)) 2020. Re-use permitted under CC BY-NC. No commercial re-use. See rights and permissions. Published by BMJ.

\section{INTRODUCTION}

Vietnam is experiencing a significant change in its economic conditions, such a change has been accompanied by significant changes in the pattern of morbidity and mortality. The country's Gross Domestic Product (GDP) is increasing at a fast pace: from US\$31 176000 000 in 2000 to US\$241 272000000 in 2018; and the country has experienced remarkable gains in combatting poverty and hunger. Gross National Income per capita has increased from US $\$ 110$ in 2000 to US\$2400 in $2018 .{ }^{1}$ At the moment the country is ranked in the low middle income countries by the world population review. Parallel with the economic growth, the country has experienced a fast and wide process of urbanisation. Over the past 20 years, more and more Vietnamese have moved from the rural areas to large urban areas with a projected urbanisation rate of $40 \%$ by early 2020 . The rapid urbanisation has been accompanied by environment deterioration, increased air pollution, deterioration of lifestyle habits (including physical inactivity and diet changes) and a big strain in healthcare services. ${ }^{2-4}$ This remarkable financial success has been accompanied by a significant reduction in communicable diseases that have been substituted in the ranking of major causes of mortality and morbidity by non-communicable diseases (NCDs), as shown in figure 1 . The burden of communicable diseases in Vietnam has significantly diminished from representing $38 \%$ and $33 \%$ of the morbidity and mortality burden in 1996 to a projected $18 \%$ and $6 \%$, respectively, in 2026 . The projected mortality burden of $6 \%$ for communicable diseases is significantly lower than the projected average burden for other countries in South East Asia (SEA). The successful efforts in combatting communicable diseases has been the main reason for the observed increase in life expectancy. The average life expectancy in Vietnam in 2017 was 79.2 years for women and 70 years for men, with an increase of (6.5 years in women and 5 years in men between 1990 and 2017). Vietnam is one of SEA countries with the highest number of elderly individuals $(60+)^{5}$ (11 million people, representing $11.95 \%$ of the population in 2017). Two million out of these 11 million people are over 80 years old. It is estimated that in 2038 the elderly will represent approximately $20 \%$ of the population. This rapid and significant shift in the age distribution of the population will create a significant increase in the demand of healthcare services for elders.

The shift in some of the leading causes of death is represented in table $1 .{ }^{6} 7$ Cardiovascular disease (CVD) represents the most important cause of death followed by cancer. In terms of both death and disability, CVD remains the first cause followed by road

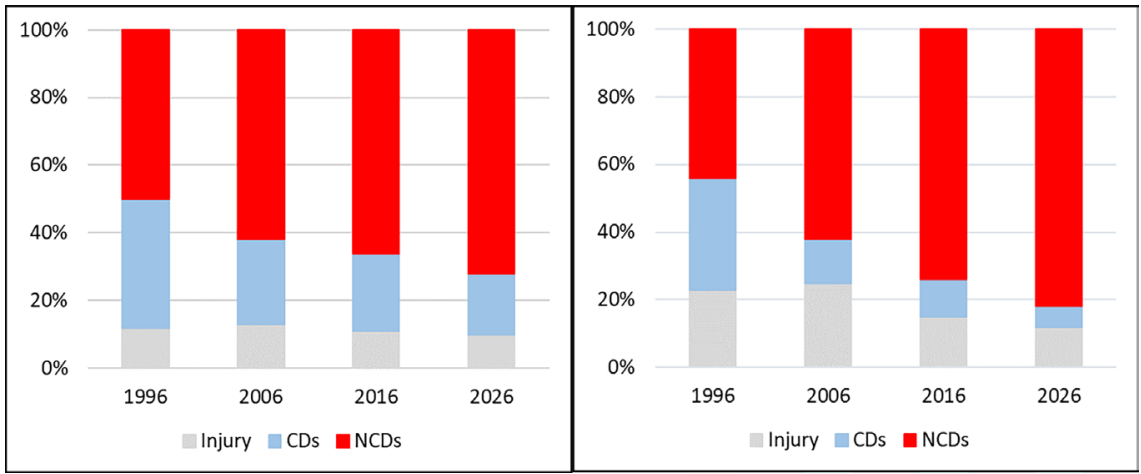

Figure 1 Change in morbidity and mortality pattern in Vietnam 1996 to 2026. CDs, communicable diseases; NCDs, non-communicable diseases. 
injuries, diabetes and lung cancer. For CVD, the leading cause of death and disability is stroke followed by ischaemic heart disease (IHD), these two causes of death represent by themselves the two leading single cause of death in Vietnam. Road injuries represent the third leading cause of death and disability.

This shift has resulted in a parallel shift in healthcare expenditures with the expenditures for NCD representing the biggest single cause of health expenditures in 2013 (table 2).

Cancers represent the second leading cause of death, with liver cancer being the leading cause of death in men and breast cancer in women. In terms of prevalence, table 3 showed that liver and lung cancer represent the most prevalent cancers in men while breast and colorectal cancer are the most prevalent cancers in women.

\section{DISEASE FACTORS}

Hypertension

Vietnam Heart Association adopted the definition of American College of Cardiology/American Heart Association of prehypertension as systolic pressure between 120 to $139 \mathrm{~mm} \mathrm{Hg}$ or diastolic pressure between 80 to $89 \mathrm{~mm}$ $\mathrm{Hg}$ and hypertension as systolic pressure more than 140 $\mathrm{mm} \mathrm{Hg}$ or diastolic pressure more than $90 \mathrm{~mm} \mathrm{Hg}{ }^{8}$

High blood pressure both prehypertension (41.8\%) and hypertension (20.7\%) prevalence is high in Vietnam, with men showing higher prevalence than women and inhabitants of rural areas showing the highest prevalence rate.

Of significant concern is the fact that only $26 \%$ of the Vietnamese are aware of their hypertension status. This challenge is particularly relevant in rural areas where only $24 \%$ of hypertensive are aware of their high blood pressure (in contrast to $38.4 \%$ in urban areas). The

\begin{tabular}{|c|c|}
\hline 1990 & 2017 \\
\hline Lower respiratory infections & Stroke \\
\hline $\begin{array}{l}\text { Haemorrhagic and other non- } \\
\text { ischaemic disease }\end{array}$ & Ischaemic heart disease \\
\hline Preterm birth complications & Lung cancer \\
\hline Congenital anomalies & $\begin{array}{l}\text { Chronic obstructive } \\
\text { pulmonary disease }\end{array}$ \\
\hline $\begin{array}{l}\text { Childhood diseases preventable } \\
\text { by vaccine (DPT, measles, chicken } \\
\text { pox) }\end{array}$ & Alzheimer's disease \\
\hline Tuberculosis & Diabetes \\
\hline Diarrhoea & Liver cirrhosis \\
\hline Drowning & Road injuries \\
\hline Iron-deficiency anaemia & $\begin{array}{l}\text { Lower respiratory } \\
\text { infections }\end{array}$ \\
\hline Unipolar depressive disorders & Tuberculosis \\
\hline
\end{tabular}

DPT, diphtheria, pertussis, tetanus. data on control of hypertension underlines the need for educational campaigns both in the population and in the medical community. Successful treatment amounts to $32.4 \%$ of the treated hypertensives and only $2.8 \%$ of all hypertensives have their blood pressure under control. As for the awareness figures men and residents of rural areas are among the groups with lower level of control.

\section{Diabetes}

Diabetes is on the rise as well in Vietnam with the number of Vietnamese with diabetes increasing steadily over time. Unfortunately the projections indicate that this rise will continue in the foreseeable future with prevalence of diabetes almost doubling between $2010(2.9 \%)$ and 2030 (4.4\%) (figure 2). ${ }^{910}$

\section{Hyperlipidaemia}

National surveys reported that low-densitylipoprotein levels experienced a significant increase of $36.6 \%$ in 2017 comparing to levels of 2007.

\section{LIFESTYLE FACTORS}

Lifestyle factors like diet and nutrition, physical inactivity, smoking and alcohol uses also contribute significantly to the death and disability burden in Vietnam. ${ }^{11}$

\section{Diet and nutrition}

The traditional Vietnamese diet is considered to be a healthy one. Like many Asian diets, the Vietnamese diet is low in fat, with small amounts of meat and fish, and rich in vegetables, with regional variation and a higher consumption of vegetables in the northern regions. ${ }^{11} 12$ The healthy profile of the traditional Vietnamese diet from the cardiovascular point of view is confirmed by the data from the 2015 national survey on the risk factors for non-communicable disease that indicate that Vietnamese adults have low average levels of serum cholesterol (181.8 $\mathrm{mg} / \mathrm{dL}$ in women and $166.3 \mathrm{mg} / \mathrm{dL}$ in men). Unfortunately, the national nutrition surveys indicate that the diet of Vietnamese is rapidly changing and while great improvement have been made in the past 20 to 30 years in improving micronutrient and macronutrient deficiencies,

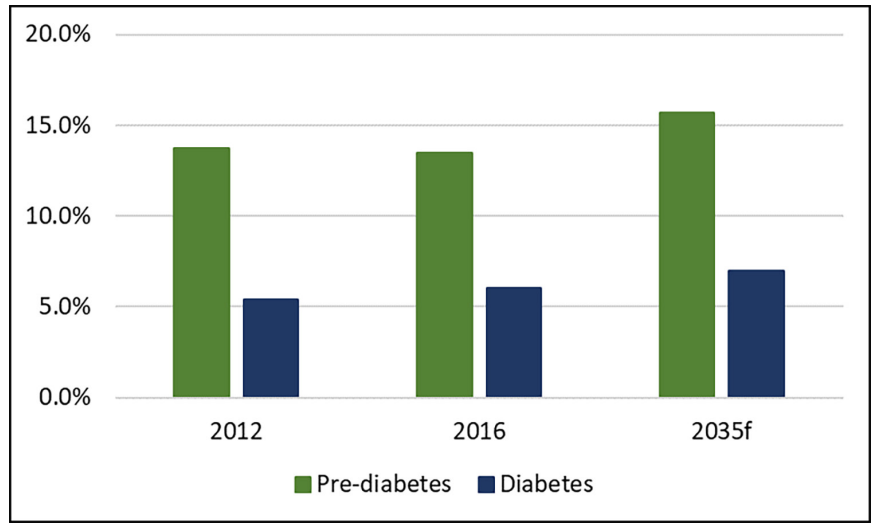

Figure 2 Prevalence of diabetes in Vietnam temporal trends. 
the data show a significant increase in the percentage of food intake from animal sources from $12 \%$ in 1985 to $21 \%$ in 2010 . The mean intake per capita per day of meat and poultry steadily increased from $11 \mathrm{~g}$ in 1985 to $84 \mathrm{~g}$ in 2010. Oil and fat consumption increased $500 \%$ between 1985 and 2010. On the contrary consumption of vegetables has gradually decreased from $214 \mathrm{~g} /$ capita/day in 1985 to $190 \mathrm{~g} /$ capita/day in $2010 .{ }^{13}$ The recent wave of fast food products brought into the country by international operators is imposing a significant and rapid shift in the dietary habits of Vietnamese and a further worsening of the traditional habits of men and women, especially in the young age groups.

\section{Physical inactivity}

The traditional life of Vietnamese is characterised by high-calorie-expenditure, due mostly to rural work and manual labour. These pattern is rapidly changing due to the rapid urbanisation and the type of jobs and work activities that characterise work in an urban setting. In order to replace the calories traditionally expended in work activities, urban Vietnamese need to focus on increasing their leisure physical activity. Unfortunately, data from a survey from the Ministry of Health shows that $70 \%$ of adult Vietnamese do not engage in vigorous physical activity and that office workers walk, on average, only 600 steps a day, instead of the recommended 10000 . A recent international study places Vietnam among the countries in the world with the lowest average number of steps walked on a daily basis. More worrisome are the data showing that the new generations of Vietnamese have adopted a lifestyle characterised by high level of sedentary behaviour with only $18 \%$ of fifth graders in Ho Chi Minh City meeting the physical activity guidelines.

\section{Overweight and obesity}

Of particular concern are the temporal trends in overweight and obesity with prevalence increasing 550\% nationally between 1993 and 2015, as shown in figure 3 . The highest prevalence of overweight and obesity is observed in urban areas and in women older than 35 years of age. While the absolute values of the prevalence of obesity are still significantly lower than many industrialised countries, the rapid increasing trends are of concern.

\section{Salt}

Unfortunately, while the Vietnamese traditional diet can be considered healthy from the point of view of the sources and the amount of fats and vegetables, it is characterised (like many other traditional Asian diets) by a high intake of salt. Vietnamese studies indicate that the average daily consumption of salt is approximately 18 to $22 \mathrm{~g} /$ day, an amount that is significantly more than the WHO recommended daily intake of $5 \mathrm{~g} /$ day. ${ }^{14}$ Major sources of salt intake in Vietnam are instant noodles and canned foods. Unfortunately, the popular and beloved morning food: pho, may represent by itself a significant

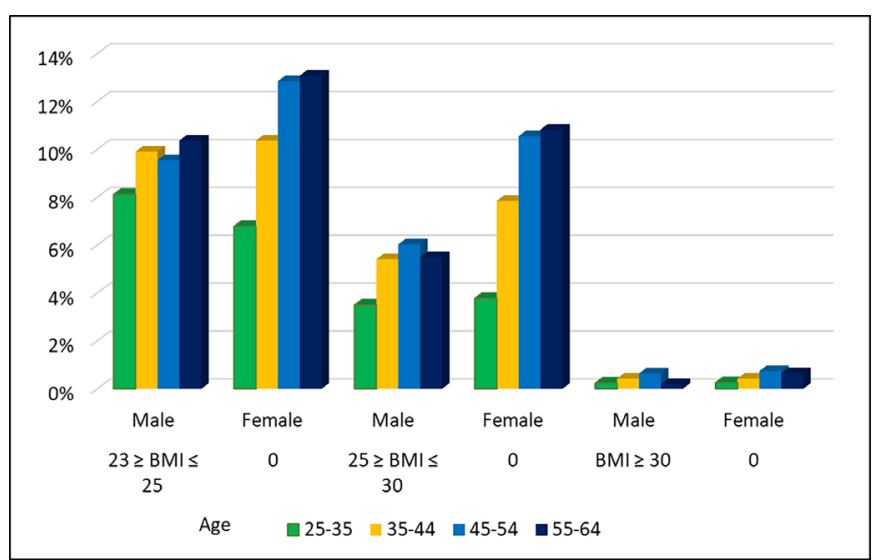

Figure 3 Prevalence of overweight and obesity by age and gender. BMI, body mass index.

source of salt in the diet of Vietnamese with an average content of 2 to $3 \mathrm{~g}$ salt in a bowl.

\section{Alcohol}

Vietnam has experienced a significant change in the consumption of alcohol that has paralleled the observed improvement in GDP. Vietnam represents the third largest beer consumer in Asia and the per capita consumption of liquor has increased $90 \%$ between 2010 and 2017 . Vietnamese men drink when celebrating occasion including Lunar New Year, holidays, wedding, housewarmings as well as in regretful circumstance like funeral or death anniversaries. In addition, alcohol is used to facilitate business transactions. Heavy drinkers comprises of 25.1\% of Vietnamese males above the age of 15 . The effects of this heavy drinking are seen with the high level of liver cirrhosis and road traffic injuries. Prevalence of alcohol use disorders and dependence are reported to be around $9.8 \%$ and $5.9 \%$, respectively. The alcohol-attributable year of life lost score for Vietnam is 4, higher compared with other countries in the region. ${ }^{15}{ }^{16}$ In addition, alcohol consumption is associated with other dangerous behaviours like smoking and unprotected sex. ${ }^{15}$ Drinking and driving is responsible for $75 \%$ of deaths due to road traffic injuries. The government has enacted a number of national interventions in order to reduce the harms related to alcohol use and abuse (ie, excise tax on alcohol, legal minimum age of 18 for purchasing and consumption of alcoholic beverages). The latest intervention has been implemented on $1^{\text {st }}$ January 2020 lowering the level of alcohol content for driving while intoxicated to less than $0.05 \mathrm{~g} / 100 \mathrm{~mL}$. As previously indicated, it appears that this intervention may have reduced the number of road accidents but not the fatality rate.

\section{Active and passive smoking}

Smoking is an important risk factors for numerous causes of death and disability. As for the other lifestyle risk factors the figures are worrisome especially in men, with the most recent data showing a prevalence of smoking of approximately $45 \%$ in men and $1.1 \%$ in women. These figures represent a $5.3 \%$ reduction from the 2010 figures. 


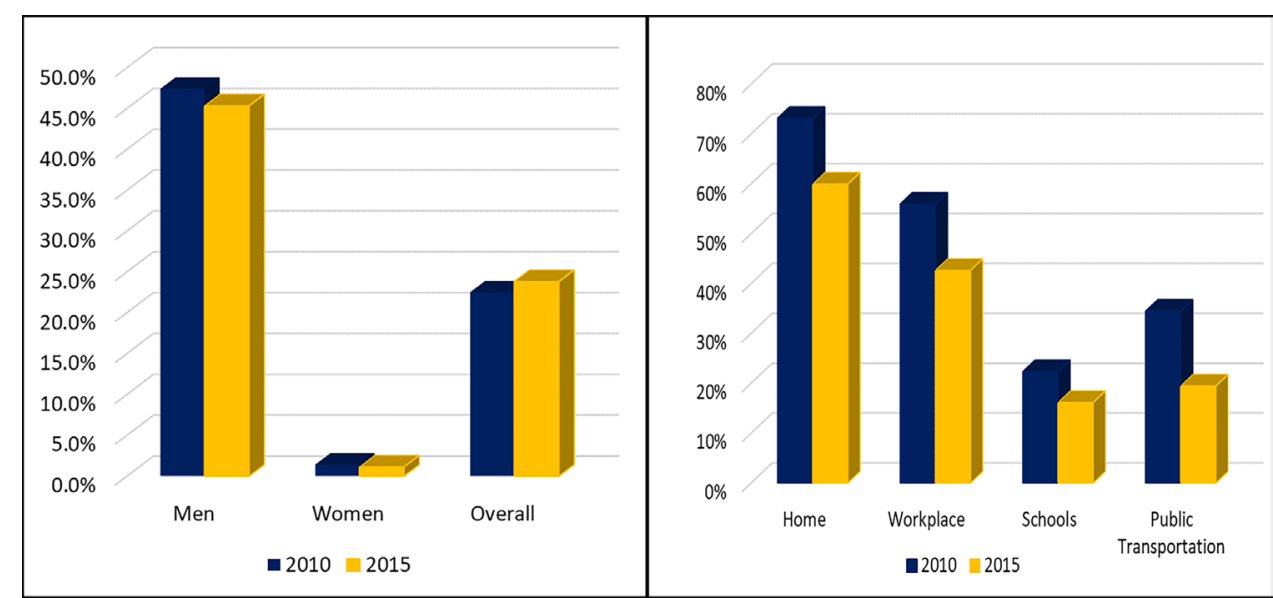

Figure 4 Prevalence of active and passive tobacco smoking.

While the trends are favourable, the observed reduction was lower than expected and efforts need to intensify in order to accelerate this positive trends. ${ }^{17}$

The high prevalence of smoking is relevant not only for the smokers themselves but for all the people who are unintentionally exposed to passive smoking. Data from the World Bank indicates that home and workplace are the leading source of secondhand smoking exposure in Vietnam with $67.6 \%$ of non-smokers exposed in their homes and $49 \%$ exposed in the workplace (figure 4 ). ${ }^{18}$

\section{ENVIRONMENTAL FACTORS}

\section{Air pollution}

Finally, in addition to individually determined exposure based on lifestyle habits we need to consider environmental exposures that affects the life and the quality of life of individuals and communities in Vietnam. Among

\begin{tabular}{lr}
\hline Table 2 Health expenditure by disease types \\
\hline Total health expenditure & $\mathbf{2 1 1 9 6 5}$ \\
\hline Non-communicable diseases & 38880 \\
\hline Digestive & 7544 \\
\hline Cardiovascular diseases & 4590 \\
\hline Genitourinary system & 3603 \\
\hline Hypertensive & 3324 \\
\hline Others & 19819 \\
\hline Communicable diseases & 24162 \\
\hline Respiratory infections & 11485 \\
\hline Diarrhoeal diseases & 3750 \\
\hline HIV/AIDS, sexually transmitted diseases & 2987 \\
\hline Neglected tropical diseases & 1568 \\
\hline Others & 4372 \\
\hline Maternal Health & 15450 \\
\hline Injuries & 1933 \\
\hline Nutritional deficiencies & 257 \\
\hline Other/unspecified diseases & 116393 \\
\hline
\end{tabular}

these, air pollution represents a significant threat both for the significant impact it has on human health and the significant exposures present in Vietnam especially in urban areas.

Air pollution has been linked, among many other diseases, to CVD, lung disease and cancer and acute lower respiratory infection in children.

SEA is the part of the world were air pollution and its health sequelae are significantly higher than other parts of the world and, unfortunately temporal trends indicate that this negative primacy has not been adequately addressed.

Data from Vietnam indicate that transportation and industrial production represent the major causes of production of carbon monoxide, nitric oxide, sulphur oxide and volatile organic compounds, an important target for prevention strategies (table 4). ${ }^{19}$

\section{Road injuries}

Despite the decreasing trend of death related to road injuries in six consecutive years since 2012, their mortality toll is still relatively high. In 2018, 24970 people died from traffic injuries in Vietnam. It is one of the leading causes of death and in the top three of premature death after stroke and ischaemic heart diseases. The burden for road injuries are among the top five causes of health expenditure. Drinking and driving and the non-use of helmet are considered the two major causes of traffic-related injuries. Other causes include use of mobile phones while driving, and the quality of helmets for motorcycle riders. The issuance of the obligatory helmet law in 2007 by the government resulted in a significant decrease in traffic injuries. ${ }^{20}$ Since $1^{\text {st }}$ January 2020 the government has implemented a new law of alcohol harm prevention that appears to have reduced the number of road injuries by $18 \%$ in the period of celebration of the Lunar New Year of 2020 comparing to that of 2019 (Vietnam Ministry of Health report). Unfortunately, during the same period, mortality from road injuries has increased by $12 \%$. The data indicates that this new traffic safety law has had some impact, but there is need to further evaluate this 
Table 3 Cancer prevalence in Vietnam

\begin{tabular}{|c|c|c|c|}
\hline & Males & Females & Both sexes \\
\hline Population & 47755412 & 48735730 & 96491142 \\
\hline Number of new cancer cases & 90822 & 73849 & 164671 \\
\hline Number of cancer deaths & 70888 & 43983 & 114871 \\
\hline $\begin{array}{l}\text { Risk of dying from cancer before the } \\
\text { of age } 75 \text { years }(\%)\end{array}$ & 15.1 & 7.8 & 11.1 \\
\hline 5-year prevalent cases & 138602 & 161431 & 300033 \\
\hline \multirow{2}{*}{$\begin{array}{l}\text { Top five most frequent cancers } \\
\text { excluding non-melanoma skin cancer } \\
\text { (ranked by cases) }\end{array}$} & Liver & Breast & Liver \\
\hline & Nasopharynx & Liver & Colorectum \\
\hline
\end{tabular}

discrepancy between the reduction in road injuries and the increase in road fatalities.

\section{REFLECTIONS, COMMENTS AND CONCLUSIONS}

Cardiovascular disease is the leading killer in Vietnam with its two major components: stroke and IHD, representing by themselves the leading causes of death. At a variance with what is seen in industrialised countries stroke claims more victims than IHD every year. This pattern is not unique to Vietnam and is shared by other countries in SEA and the rest of Asia (eg, China). The reason for this primacy of stroke over IHD are not known but it has been observed and discussed for a number of years. Many hypotheses have been put forward including the relatively low intake of protein and the high intake of salt. The diet heart hypothesis suggests that the impact of hypertension, diabetes, smoking and other risk factors in a population characterised by a low atherogenic diet is more significant in the arteries of the brain than in those of the heart. As the diet of these countries changes toward a more westernised diet the CVD pattern changes and IHD becomes more prominent than stroke. ${ }^{2122}$ The success in the prevention and treatment of communicable diseases has been the most critical force behind the observed increase in life expectancy of Vietnamese. The challenge the nation faces now, in order to ensure that this gain in life expectancy, morbidity and disability is sustained and improved, is to avoid the worsening of the lifestyle habits that are major risk factors for cardiovascular disease and to successfully treat the conditions (eg, high blood pressure, diabetes, high blood cholesterol) that are major causes of IHD, stroke, other CVD manifestations and other debilitating chronic conditions and causes of death. The figures regarding the prevalence, awareness and control of hypertension are alarming especially the very low level of hypertensives who are aware, under treatment and successfully controlled. These figures indicate the need to implement education strategies for both the community at large and the healthcare professionals.

Diabetes is increasing as well with its prevalence estimated to almost double by 2030. Low level of physical activity, overweight and obesity play an important role in determining the projected increase.

Unfortunately, as described, the major lifestyle habits of Vietnamese are quickly changing toward an unhealthier pattern that will affect the long-term improvements observed to date in Vietnam.

The westernisation of the traditional Vietnamese diet with its high density of calories, and high content of fats, animal fats, simple sugars, low intake of fruits and vegetables will eventually be reflected in an increase in cardiovascular disease burden, especially if this is not accompanied by comprehensive strategies to prevent and successfully treat high blood pressure and diabetes and successful

Table 4 Estimated emission of pollutants from major sources in Vietnam in 2015 (tonnes/year)

\begin{tabular}{lcccc}
\hline Production field & Carbonmonoxide & Nitricoxide & Sulphur oxide & Volatileorganic compounds \\
\hline Thermoelectric & 6.562 & 65.263 & 131.665 & 2.489 \\
Industrial production & 74.004 & 182.061 & 315.588 & 1.598 \\
Transportation & 495.952 & 112.856 & 38.122 & 67.863 \\
\hline
\end{tabular}


campaign to reduce smoking and its powerful deleterious impact not only on smokers but to those who live and work around them. Overweight and obesity prevalence are low in Vietnam and the current figure place Vietnam among the countries in the world with the lowest prevalence of obesity, however the trend observed are worrisome and if unchecked the current trends will seriously impact the health of the Vietnamese people. Smoking and heavy alcohol consumption represent a significant public health challenge that is limited, for the most part to men in both rural and the urban areas. Education and prevention strategies have been implemented but their success to date has been minimal.

Finally, air pollution represents a significant threat to human health and well-being in whole SEA and Vietnam in particular. In the urban areas, traffic represents a significant source of air pollution. The best approach to address this use is by increasing the public transportation options, especially those with low emission (train, electric buses and so on). The reduction of high emitting cars, scooters and motorcycle can significantly improve the air quality of urban areas. Another significant source of air pollution in Vietnam is the industry and the thermal electricity generation through coal-fired plants especially with regard to nitricoxide and sulphur oxide.

Recognising the effects of harmful use of alcohol, tobacco smoking, pollution, nutrition and life style change on people health, Vietnam government has enacted policies and regulations to reduce these risk factors. Recently the government strengthened the laws that can prevent alcohol abuse and its health consequences, these include: severe penalties for drinking and driving, sale of alcoholic beverages not allowed to individuals under 18 years of age, stores and restaurants nearby hospitals and schools are not allowed to sell alcohol, prohibition of advertisement for alcohol products with an alcohol content of 15 degrees or more. These legislative efforts have been coupled with educational campaigns like those aimed at educating people to control their alcohol consumption and to learn skills that would allow individuals to refuse if they are pressured to drink by the social circumstances. The law on tobacco harm prevention aimed at reducing smoking and its harmful effects has been in place since 2012 and include the banning of tobacco advertising, the setting of 18 as the age for the purchase of tobacco products, ban of cigarette vending machine. In term of traffic safety, in 2007 the law mandating the use of helmet for motorbikes/scooters drivers was enacted and since then the country has experienced a $4.6 \%$ reduction in fatalities due to road accidents.

Vietnam is a dynamic country that is experiencing a fast and significant change in its economy with dramatic modifications in the economic and social conditions of many Vietnamese. This transformation has been associated with significant changes in the pattern of morbidity and mortality with a significant increase of life expectancy (21 years over the past 50 years) and a predominance chronic diseases as the main cause of death and disability. It is important, in order to sustain and improve the gains in life expectancy, to address the environmental and lifestyle risk factors that have been identified as playing a major role in the aetiology and pathogenesis of chronic diseases. The current trends in these risk factors is unfavourable, and it is important that a multipronged approach be embraced by individuals and communities; an approach that includes legislative action and education campaigns, aimed at the public and healthcare professionals, that will help in understanding the health impacts of behaviours and the critical importance of preventing and treating them when identified.

Acknowledgements Our thanks to the anonymous peer reviewers whose suggestions have significantly improved this manuscript.

Contributors MT planned the study and is responsible for overall content. MT and TTN drafted and revised the manuscript. TTN submitted the manuscript.

Funding The authors have not declared a specific grant for this research from any funding agency in the public, commercial or not-for-profit sectors.

Competing interests None declared.

Patient consent for publication Not required.

Provenance and peer review Not commissioned; externally peer reviewed.

Data availability statement Data are available in a public, open access repository. All data relevant to the study are included in the article or uploaded as supplementary information. All the data used to discuss in this article are available in the public and open access repository. The repository includes data from World Bank (https://data.worldbank.org/indicator/NY.GDP.MKTP.CD?locations=VN, https:// www.worldbank.org/en/country/vietnam/overview, https://data.worldbank.org/ indicator/SP.DYN.LE00.IN?locations=VN), Institute for Health Metrics and Evaluation, 2017 (http://www.healthdata.org/vietnam), 10.11. General Statistics Office (Vietnam), Ministry of Health (Vietnam), National Institute of Nutrition (Vietnam), United Nations Children's Fund (UNICEF) (http://viendinhduong.vn/FileUpload/ Documents/Summary_report_gns_2009-2010_chuan.PDF), Vietnam Ministry of Health (http://jahr.org.vn/downloads/JAHR2014/JAHR202014_EN_full.pdf), WHO (https://www.who.int/substance_abuse/publications/global_alcohol_report/profiles/ vnm.pdf?ua=1;https://apps.who.int/iris/handle/10665/43007http://jahr.org.vn/ downloads/JAHR2014/JAHR202014_EN_full.pdf) and other journals including Hypertension, British Journal of Nutrition, Traffic Injury Prevention, Asia Pacific Journal of Clinical Nutrition, European Journal of Clinical Nutrition, Drug Alcohol Depend, Diabetes Res Clinical Practice, International Journal of Public Health, International Journal of Scientific \& Technology Research, Journal of Atherosclerosis and Thrombosis.

Open access This is an open access article distributed in accordance with the Creative Commons Attribution Non Commercial (CC BY-NC 4.0) license, which permits others to distribute, remix, adapt, build upon this work noncommercially, and license their derivative works on different terms, provided the original work is properly cited, appropriate credit is given, any changes made indicated, and the use is non-commercial. See: http://creativecommons.org/ licenses/by-nc/4.0/.

ORCID iD

Tuyet Thi Nguyen http://orcid.org/0000-0002-2686-6895

\section{REFERENCES}

1 The World Bank. World bank national accounts data, and OECD national accounts data files, 2018. Available: https:// data.worldbank.org/indicator/NY.GDP.MKTP.CD?locations=VN [Accessed Feb 2020].

2 The World Bank. The world bank in Vietnam. Available: https://www. worldbank.org/en/country/vietnam/overview [Accessed Feb 2020].

3 Brennan EM. Population, urbanization, environment, and security: a summary of the issues, environmental change and security project report. 5, 1999.

4 Bui TV, Blizzard CL, Luong KN, et al. Fruit and vegetable consumption in Vietnam, and the use of a 'standard serving' size to measure intake. Br J Nutr 2016;116:149-57. 
5 The World Bank. Life expectancy at birth, total (years) - Vietnam, 2017. Available: https://data.worldbank.org/indicator/SP.DYN.LE00. IN? locations=VN [Accessed Feb 2020].

6 Institute for Health Metrics and Evaluation, 2017. Available: http:// www.healthdata.org/vietnam [Accessed Feb 2020].

7 Ministry of Health; Health Partnership Group. Joint annual health review 2014: strengthening prevention and control of noncommunicable disease. Available: http://jahr.org.vn/downloads/ JAHR2014/JAHR\%202014_EN_full.pdf [Accessed 06 Apr 2020].

8 Chobanian AV, Bakris GL, Black HR, et al. Seventh report of the joint National Committee on prevention, detection, evaluation, and treatment of high blood pressure. Hypertension 2003;42:1206-52.

9 Shaw JE, Sicree RA, Zimmet PZ. Global estimates of the prevalence of diabetes for 2010 and 2030. Diabetes Res Clin Pract 2010;87:4-14.

10 Pham NM, Eggleston K. Prevalence and determinants of diabetes and prediabetes among Vietnamese adults. Diabetes Res Clin Pract 2016;113:116-24.

11 Dien LN, Thang NM, Bentley ME. Food consumption patterns in the economic transition in Vietnam. Asia Pac J Clin Nutr 2004;13:40-7.

12 Thang NM, Popkin BM. Patterns of food consumption in Vietnam: effects on socioeconomic groups during an era of economic growth. Eur J Clin Nutr 2004;58:145-53.

13 Nguyen TT, Hoang MV. Non-Communicable diseases, food and nutrition in Vietnam from 1975 to 2015: the burden and national response. Asia Pac J Clin Nutr 2018;27:19-28.

14 General Statistics Office (Vietnam), Ministry of Health (Vietnam), National Institute of Nutrition (Vietnam), United Nations Children's
Fund (UNICEF). Vietnam General nutrition survey 2009-2010. Available: http://viendinhduong.vn/FileUpload/Documents/ Summary_report_gns_2009-2010_chuan.PDF [Accessed Feb 2020].

15 World Health Organization. Global alcohol report - Vietnam, 2016. Available: https://www.who.int/substance_abuse/publications/ global_alcohol_report/profiles/vnm.pdf?ua=1 [Accessed Assessed February, 2020].

16 Lincoln M. Alcohol and drinking cultures in Vietnam: a review. Drug Alcohol Depend 2016;159:1-8.

17 Van Minh H, Giang KB, Ngoc NB, et al. Prevalence of tobacco smoking in Vietnam: findings from the global adult tobacco survey 2015. Int J Public Health 2017;62:121-9.

18 Marquez P V, Krasovsky K, Andreeva T, et al. Vietnam - Overview of Tobacco Use, Tobacco Control Legislation and Taxation. Washington, D.C: World Bank Group, 2019. http://documents.worldbank.org/ curated/en/818741559223994957/Nietnam-Overview-of-TobaccoUse-Tobacco-Control-Legislation-and-Taxation

19 Hoang TA, Chu NX, Tran TV. The environmental pollution in Vietnam: source, impact and remedies. IJSTR 2017;6.

$20 \mathrm{Ha} \mathrm{NT}$, Ederer D, Vo VAH, et al. Changes in motorcycle-related injuries and deaths after mandatory motorcycle helmet law in a district of Vietnam. Traffic Inj Prev 2018;19:75-80.

21 MacKay J, Mensah G. The atlas of heart disease and stroke. World Health Organization, 2004. https://apps.who.int/iris/handle/10665/ 43007

22 Tada N, Maruyama C, Koba S, et al. Japanese dietary lifestyle and cardiovascular disease. J Atheroscler Thromb 2011;18:723-34. 